\title{
Ultrasound and endocrine evaluation of the ovarian cycle and early pregnancy in the Sumatran rhinoceros, Dicerorhinus sumatrensis
}

\author{
T. L. Roth¹, J. K. O'Brien' ${ }^{1}$, M. A. McRae' ${ }^{1}$ A. C. Bellem², \\ S. J. Romo ${ }^{1}$, J. L. Kroll ${ }^{1}$ and J. L. Brown ${ }^{2}$ \\ ${ }^{1}$ Center for Research of Endangered Wildlife, Cincinnati Zoo and Botanical Garden, \\ Cincinnati, OH 45220, USA; and ${ }^{2}$ Conservation and Research Center, National Zoological \\ Park, Smithsonian Institution, Front Royal, VA 22630, USA
}

Longitudinal ultrasound and endocrine evaluations were conducted in two adult female Sumatran rhinoceroses (Dicerorhinus sumatrensis) over a period of 12-22 months to learn more about their reproductive physiology. Rectal ultrasonography was conducted to monitor ovarian activity. Blood samples were collected and analysed for progesterone and $\mathbf{L H}$, and faecal samples were analysed for progestin metabolites. One female showed cyclic ovarian activity during the study period, whereas the other female showed no evidence of ovarian activity. The cyclic Sumatran rhinoceros appeared to be an induced ovulator, the first of its kind reported within the Perrisodactyla. Ultrasound examinations of the ovaries revealed the formation of anovulatory haemorrhagic follicles when the animal was not mated. These follicles appeared to undergo varied degrees of luteinization that resulted in irregular faecal progestin profiles.
When allowed to mate, the female showed a 21 day reproductive cycle that was reflected in both faecal progestin and serum progesterone profiles. The concentration of serum LH was baseline before mating, increased approximately 30-fold within 1-2 $\mathrm{h}$ of intromission and returned to baseline within $22 \mathrm{~h}$. Ovulation occurred within $46 \mathrm{~h}$ of copulation. The female conceived three times during the study. Pregnancy was detected using ultrasonography 14-16 days after mating, and the concentration of both serum progesterone and faecal progestins remained high. Early embryogenesis appeared to be similar to that in horses. However, each pregnancy terminated unexpectedly within the first 3 months of gestation. This study demonstrates the important role that basic research and reproductive technology can play in developing a natural breeding programme for an endangered animal in captivity.

\section{Introduction}

Of the five rhinoceros species in existence, all but the South African white rhinoceros are considered endangered (IUCN, 1996). The decimation of this taxon can be attributed to previous uncontrolled hunting and current illegal poaching for the horn of the animal, which in some Asian cultures is believed to possess medicinal properties. The Sumatran rhinoceros (Dicerorhinus sumatrensis) is the most primitive of surviving rhino species and descended from the woolly rhinoceros that lived during the last ice age. The Sumatran rhinoceros is also the most endangered: there are fewer than 400 animals worldwide and populations continue to dwindle (Foose and Reece, 1998). A captive breeding programme was initiated for this species and from 1984 to 1996, 40 animals were placed in zoos and reserves worldwide after being rescued from snares or forests destroyed by logging (Foose and van Strien, 1997).

Email: terri.roth@cincyzoo.org
Continued support for these Sumatran rhino breeding programmes is uncertain because zoos and reserves have not yet been successful in propagating the species.

Breeding the Sumatran rhinoceros in captivity has been difficult for several reasons. Firstly, there is little information available about their natural behaviour or reproduction because wild animals are reclusive and solitary. Furthermore, the captive population has always been small (there are currently just 17 animals in captivity worldwide; Foose and Reece, 1998) and composed largely of animals of unknown age and fertility. However, it is known that aggressive interactions, which can result in serious physical injury, often take place between males and non-oestrous females (Kahn et al., 1999). Since females do not appear to show overt oestrous behaviour, knowledge of basic reproductive processes and the ability to determine the periovulatory period could significantly enhance the potential to breed this species in captivity.

Studies have been conducted in black and white African rhinoceroses by analysing faecal progestin 
metabolites to characterize reproductive cyclicity and detect pregnancy (Schwarzenberger et al., 1993, 1998; Berkeley et al., 1997; Radcliffe et al., 1997; Patton et al., 1999). Data indicate a mean duration of the reproductive cycle of 25 days for the black rhinoceros, whereas data for the white rhinoceros are more difficult to interpret. According to studies involving faecal hormone analyses and behavioural data, both 30 day and 70 day reproductive cycles have been reported (Radcliffe et al., 1997; Schwarzenberger et al., 1998; Patton et al., 1999; Roth and Brown, 1999). In one case in which ultrasonography was used to assess ovarian activity directly while monitoring faecal progesterone metabolites, a cycle duration of 33 days was determined (Radcliffe et al., 1997). Reproductive cyclicity in the Indian rhinoceros has been studied by monitoring urinary hormone metabolites and matching data to behavioural oestrus (Kasman and Lasley, 1981; Kasman et al., 1986; Hodges and Green, 1989). In this Asian rhinoceros species, the duration of the ovarian cycle appears to vary significantly, ranging from 39 to 64 days (Kasman and Lasley, 1981; Roth and Brown, 1999). A recent report by Heistermann et al. (1998) determined that nearly all progesterone is metabolized and excreted in the faeces of Sumatran rhinoceroses. A 25 day reproductive cycle was described in a single female based on the number of days between two progestin peaks detected by faecal metabolite analysis (Heistermann et al., 1998). Together, these studies demonstrate species diversity with regard to reproductive cyclicity among Rhinocerotidae.

The present study was conducted at the Cincinnati Zoo and Botanical Garden on a group of three Sumatran rhinoceroses, the only animals of this species in captivity outside Asia. The overall aim was to characterize aspects of female reproductive physiology that would help in developing a successful natural breeding programme. Specific objectives were to: (i) characterize ovarian activity by ultrasonography; (ii) evaluate serum progesterone and $\mathrm{LH}$ concentrations during the oestrous cycle, mating and pregnancy; (iii) validate a faecal progestin metabolite assay for non-invasive monitoring of ovarian activity; (iv) develop a successful strategy for breeding the females naturally; and (v) document early pregnancy.

\section{Materials and Methods}

\section{Animals}

Three Sumatran rhinoceroses (two females, one male) were used in this 22 month study. Animals were on loan to the United States from the Indonesian Government and represent the entire population outside Southeast Asia. The male (SB no. 28) was caught in the wild as an adult and was estimated to be $>20$ years old. One female (SB no. 27) from the Bronx Zoo was caught in the wild as an adult and was also estimated to be $>20$ years old. The second female (SB no. 29) was caught in the wild as a juvenile and raised at the Los Angeles Zoo. Both females were transferred to the Cincinnati Zoo and Botanical Garden on breeding loan and were maintained there throughout the study.

Each Sumatran rhinoceros was provided each day with approximately $30-50 \mathrm{~kg}$ of fresh browse comprising up to ten types of Ficus and occasionally Kaffir plum, 2-3 flakes of hay $(40 \%$ alfalfa, $60 \%$ orchard grass) and $1.8 \mathrm{~kg}$ of grain (ADF16; Mazuri, St Louis, MO). Diets were supplemented with fresh fruits and vegetables, and all animals had unlimited access to a mineral block and water. Each morning animals received $6 \mathrm{ml}$ vitamin $\mathrm{E}$ supplement (Emcelle Tocopherol; 500 iu $\mathrm{ml}^{-1}$; Stuart Products Inc., Bedford, TX) orally in a banana. Animals were walked across a floor scale each day to monitor body weight. The average body weights for female no. 27, female no. 29 and the male were 600,775 and $705 \mathrm{~kg}$, respectively.

Animals were maintained individually in adjacent enclosures, except during mating introductions. Each animal had access to a stall within a heated barn. During the summer months, animals were maintained on display in an outdoor exhibit, but were allowed access to the barn at night. During the winter months, animals were allowed access to their yards (2000-2500 $\left.\mathrm{m}^{2}\right)$ for at least $1 \mathrm{~h}$ each day except during inclement weather (for example, a heavy snow fall, temperatures $\leqslant 4^{\circ} \mathrm{C}$ or severe wind chill). During the winter, the barn was heated $\left(21^{\circ} \mathrm{C}\right)$ and animals were exposed to artificial lighting from 07:00 h to 20:00 h each day.

\section{Animal introductions and mating}

No behavioural or external signs of oestrus were observed in either female rhinoceros. Introductions for mating were based on the presence of a preovulatory follicle identified during an ultrasound examination. After several months of conditioning, animals tolerated blood collection from the ear veins with a $23 \mathrm{~g}$ butterfly catheter attached to a $6 \mathrm{ml}$ syringe. Thereafter, the progesterone enzymeimmunoassay provided an additional tool for predicting the appropriate day of mating as serum progesterone concentrations could be determined within $8 \mathrm{~h}$ of blood collection. Animals were introduced when progesterone was baseline (usually $<0.05 \mathrm{ng} \mathrm{ml}^{-1}$ ) and a preovulatory follicle was present. After several matings, cyclic ovarian and endocrine patterns were established and could be used to predict the next mating after a non-conceptive copulation.

\section{Ultrasonography}

Female rhinoceroses were conditioned for several weeks to allow rectal ultrasound examinations. An Aloka 500 machine (Aloka, Wallingford, CT) connected to a video cassette recorder and a $5 \mathrm{MHz}$ linear array probe (standard equine rectal probe) was used for all examinations. A Sony thermal printer (Aloka) was used to print the images. The examination followed a standard protocol in which the bladder, cervix, uterine body, uterine horns and both ovaries were examined. Ovarian follicles and 
luteinizing follicles $\geqslant 10 \mathrm{~mm}$ in diameter were measured, and the presence of corpora lutea was recorded. Measurements were also taken of all embryonic vesicles observed. The entire examination typically lasted $\leqslant 10 \mathrm{~min}$.

Each female was examined three to seven times each week for 6 months. After the first 6 months, female no. 27 was examined once a month for another 6 months, whereas female no. 29 was subjected to more intensive monitoring that continued throughout the 22 month study period (from day 1 to day 647; Fig. 1). Female no. 29 conceived on three occasions; however, none of the pregnancies developed to term. The first pregnancy lasted about 6 weeks and the female was examined three times each week. During the second pregnancy, the female was examined every 9-18 days for 12 weeks. After the third pregnancy was detected using ultrasonography, the female was not examined again until day 30 of gestation, when pregnancy loss was determined.

\section{Collection of blood and faecal samples}

For female no. 29, freshly defecated faecal samples were collected each day from day 1 to day 375 of the 22 month study period (Fig. 1). Samples were placed in plastic tubes and stored frozen $\left(-20^{\circ} \mathrm{C}\right)$ until processed for progestin metabolite analysis. Blood samples were collected two to three times each week from August 1997 to June 1998 (from day 151 to day 480) and then each week until December 1998 (day 647; Fig. 1). For additional LH data, samples were collected each day from 5 February to 10 February 1998, and samples were collected twice (before and after mating) on two occasions when mating occurred (16 January and 8 August 1998).

For the older female (no. 27), blood sample collection was conducted two to three times each week for 5 months (from August 1997 to December 1997). Serum was obtained after centrifugation at $1315 \mathrm{~g}$ for $10 \mathrm{~min}$ and stored in $1 \mathrm{ml}$ aliquots at $-80^{\circ} \mathrm{C}$ until analysis.

\section{Serum progesterone enzymeimmunoassay}

Chemicals and hormones were obtained from Sigma Chemical Company (St Louis, MO). Serum progesterone was extracted and concentrations determined by enzymeimmunoassay following the protocol described by Munro and Stabenfeldt (1984) and using a monoclonal antibody produced against 4-pregnen-11-ol-3,20-dione hemisuccinate: BSA (provided by J. Roser, University of California, Davis, CA). Intra- and interassay coefficients of variation were 5.9 and $14.9 \%$, respectively. Parallelism with the standard curve was confirmed by comparing dilutions $(1: 1,1: 2$ and $1: 4)$ of peak luteal phase serum samples with standard dilutions. Assay sensitivity was $0.05 \mathrm{ng} \mathrm{ml}^{-1}$.

\section{Faecal progestin metabolite radioimmunoassay}

Faecal progestin metabolites were quantified using a radioimmunoassay as described by Brown et al. (1994). Faecal extracts were diluted (1:800 in PBS) and assayed $(100 \mu \mathrm{l})$ in duplicate. Parallel displacement curves were obtained by comparing serial dilutions of pooled Sumatran rhino faecal extracts with progesterone standard preparations. Interassay coefficients of variation for two separate internal controls were $11.9 \%(n=8)$ and $9.6 \%(n=8)$. Intra-assay coefficients of variation were $<10 \%$ and assay sensitivity was $3.75 \mathrm{pg} \mathrm{ml}^{-1}$.

\section{Serum $L H$ radioimmunoassay}

Serum LH was quantified according to Brown et al. (1999) using a monoclonal anti-bovine LH antibody (no. 518-B7; provided by J. Roser, University of California, Davis, CA). The antibody bound $30-40 \%$ of the iodinated tracer with approximately $4 \%$ non-specific binding. The assay was validated by demonstrating parallelism between dilutions (neat; 1:16) of pooled rhinoceros serum and the standard curve, and significant recovery (>98\%) of exogenous ovine $\mathrm{LH}$ added to rhinoceros serum. Assay sensitivity was $0.3 \mathrm{ng} \mathrm{ml}^{-1}$.

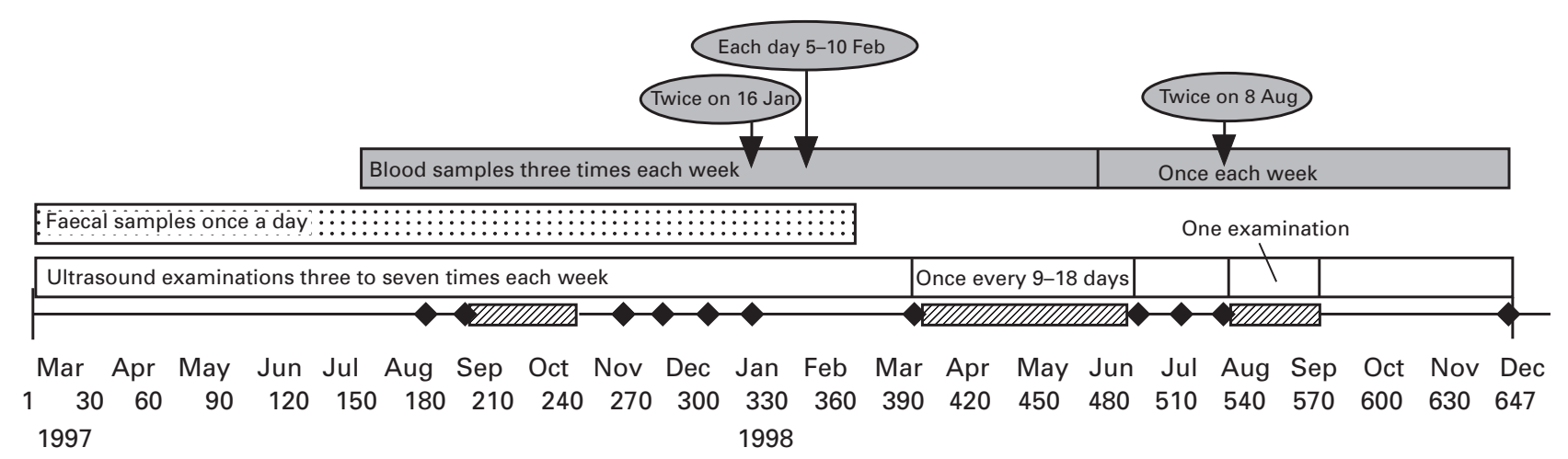

Fig. 1. Schematic representation of the sampling schedule for female Sumatran rhinoceros (Dicerorhinus sumatrensis) no. 29 throughout the 22 month study (from day 1 to day 647). The study period encompassed 11 matings $($ ) and three pregnancies (何). 


\section{Statistical analysis}

Both the size of the follicle and LH concentrations were analysed by one-way ANOVA and means within each data set were compared using a least significant difference test (Statview 5.0.1 Macintosh statistical software package) (Table 1). Faecal progestin metabolite and serum progesterone profiles were compared using Pearson's correlation coefficient test. Data are presented as means $\pm \mathrm{SD}$.

\section{Results}

\section{Animal introductions and mating}

When introduced to the female, the male showed one of three types of behaviour within $30 \mathrm{~min}$ : (i) ignoring the female; (ii) following the female at a slow and steady pace; or (iii) chasing the female. On several occasions, the male followed the female and mounted her when she appeared to be receptive, only to dismount and immediately pursue her aggressively. On these occasions, the animals were separated until the next day when introductions typically resulted in slow steady following behaviour, mounting and copulation.

Copulation typically lasted 30-50 min and the animals were separated immediately afterwards. On two occasions, a second introduction was attempted on the same day but resulted in an aggressive chase. Therefore, in subsequent cycles animals were not reintroduced after a successful mating.

\section{Ovarian activity and progesterone}

In female no. 27 , a large $(8 \mathrm{~cm} \times 10 \mathrm{~cm})$ uterine mass was observed within the uterine body and the ovaries appeared small (approximately $2.5 \mathrm{~cm} \times 4.0 \mathrm{~cm}$ ) and inactive. Ovarian structures were not observed to be developing during the 12 months of monitoring. Serum progesterone concentrations in samples collected from August to December were consistently below $0.160 \mathrm{ng} \mathrm{ml}^{-1}$ and often undetectable $\left(<0.05 \mathrm{ng} \mathrm{ml}^{-1}\right)$.
In contrast, in female no. 29, the ovaries were larger (approximately $4.5 \mathrm{~cm} \times 7.0 \mathrm{~cm}$ ) and were active throughout the study. Large follicles ( $\geqslant 50 \mathrm{~mm}$ circumference or $>15 \mathrm{~mm}$ diameter) were observed on both ovaries and were more abundant $(P<0.05)$ during periods of the study when mating was not occurring compared with periods during which the female was either mating at regular intervals or was pregnant (Table 1).

Corpora lutea were not observed during periods of the study when mating did not take place (days 1-188, 350-393 and 611-646). Instead, follicles grew to preovulatory size or greater $(79.5 \pm 11.0 \mathrm{~mm}$ circumference; $n=11$ ). Upon ovarian ballottement (Ginther, 1995), echogenic specks were visible within the follicular fluid, and fibrinous quivering bands formed shortly thereafter. The follicle appeared web-like (Fig. 2a) for an average of $15.7 \pm 4.6$ days (ranging from day 11 to day 23) before it was no longer discernible on the ovary. During the initial period of the study when mating did not occur (March-August 1997; from day 1 to day 188) faecal progestin concentrations increased to $>10 \mu \mathrm{g} \mathrm{g}^{-1}$ on several occasions. These high concentrations of progestins were similar to those associated with the luteal phase of the oestrous cycle after mating and ovulation. However, the changes in progestin concentrations during this period were more erratic and did not show a regular cyclical pattern that could be interpreted as the reproductive cycle of this female (Fig. 3a). Increased serum progesterone concentrations during intervals when mating did not take place were associated with the formation of anovulatory haemorrhagic follicles, but concentrations varied considerably and did not always reach the peak concentrations $\left(>1.0 \mathrm{ng} \mathrm{ml}^{-1}\right.$ ) observed during confirmed luteal phases. For example, progesterone concentrations increased only slightly to about $0.25 \mathrm{ng} \mathrm{ml}^{-1}$ after the formation of anovulatory follicles from February to March 1998 (from day 350 to day 393) when the female was not paired with the male for mating. In contrast, the first large increase in progesterone (Fig. 3b) was associated with the formation of a large anovulatory follicle (Fig. 2a) and did not differ in

Table 1. Average number of large ( $\geqslant 50 \mathrm{~mm}$ circumference, $>15 \mathrm{~mm}$ diameter) follicles on the ovaries of Sumatran rhinoceros (Dicerorhinus sumatrensis) number 29 observed using ultrasonography during different reproductive states

\begin{tabular}{lcc}
\hline Reproductive status & Number of follicles $(\geqslant 15 \mathrm{~mm})^{*}$ & Number of days examined \\
\hline Non-mating and non-pregnant $^{\mathrm{a}}$ & $2.40 \pm 0.99^{\mathrm{d}}$ & 134 \\
Mating and non-pregnant $^{b}$ & $0.75 \pm 0.63^{\mathrm{e}}$ & 59 \\
Pregnant $^{\mathrm{c}}$ & $0.51 \pm 0.67^{\mathrm{e}}$ & 51 \\
\hline
\end{tabular}

* Mean \pm SD number of follicles on both ovaries.

ancludes ultrasound examinations before any mating activity and during intervals when animals were not placed together for mating due to inclement weather.

bIncludes ultrasound examinations during and 3 weeks after non-conceptive matings.

Includes ultrasound examinations from the day of a conceptive mating until embryo loss was detected.

deValues that have different superscripts within the columns are significantly different $(P<0.05)$. 

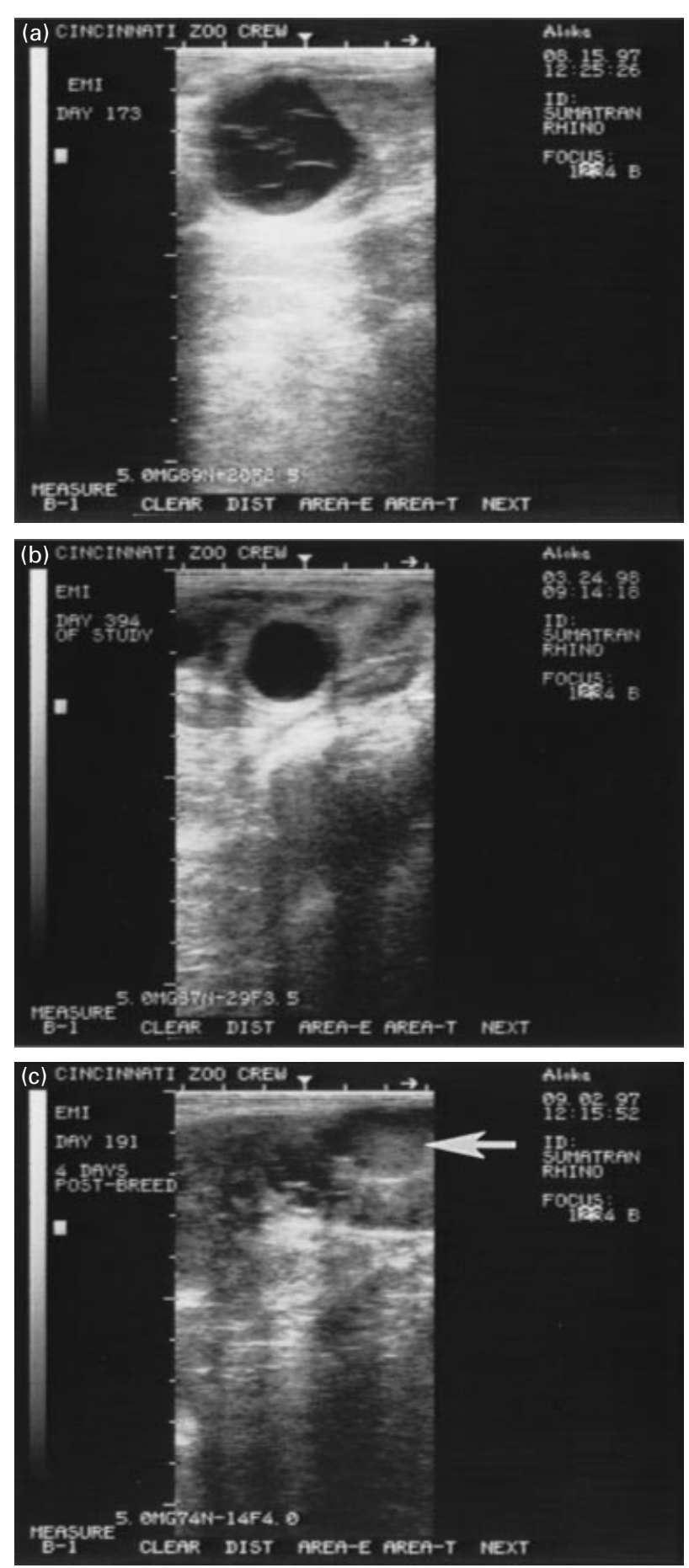

Fig. 2. Ultrasound images of ovarian structures in Sumatran rhinoceros no. 29. (a) Anovulatory haemorrhagic follicle with distinct web-like echogenic lines; (b) preovulatory follicle on the day of mating; and (c) corpus luteum (arrow) 4 days after mating, or 2 days after ovulation.

concentration or duration from that produced later in the study after mating and ovulation. On the basis of the increase in progesterone associated with the presence of these structures and their close resemblance to the haem- orrhagic and luteinizing follicles described in horses (Ginther, 1995), these follicles are referred to as luteinized follicles throughout the remainder of this paper.

On the day of mating, the largest (preovulatory) follicle was typically 20-25 mm in diameter (Fig. 2b), and serum progesterone concentrations were consistently low, often below the level of assay sensitivity $\left(<0.05 \mathrm{ng} \mathrm{ml}^{-1}\right.$; Fig. $3 \mathrm{~b})$. There were 11 successful or attempted matings during the study and all were associated with cyclical patterns of progesterone. Progesterone concentrations began to increase 3-5 days after mating, peaked at approximately $1.0 \mathrm{ng} \mathrm{ml}^{-1}\left(1.25 \pm 0.41 \mathrm{ng} \mathrm{ml}^{-1}\right) \quad 11.6 \pm 2.2$ days after mating and decreased to undetectable amounts $(<0.05 \mathrm{ng}$ $\mathrm{ml}^{-1}$ ) by 19-21 days after mating if the female was not pregnant.

Although the faecal and serum progesterone profiles were positively correlated $(P<0.05)$ during the study period when the two types of sample were evaluated concurrently (Fig. 3c), the relationship was weak $(r=0.594)$. In general, there was a lag between the changes in serum progesterone concentrations and those of faecal progestins, which on occasion exceeded 48 h. Nevertheless, faecal progestin concentrations were consistently low at the time of mating and high during the luteal phase.

During two mating encounters, the male failed to achieve full penile intromission and ejaculation despite hours of mounting and attempted penetration. Nevertheless, ovulation was confirmed after all 11 mating encounters, whereas ovulation failed to occur on all three occasions when oestrus was predicted but animals were not paired for mating. The day of ovulation was determined after nine of the mating encounters and occurred by $22(n=1)$ or $46(n=8)$ h after copulation. Typically, only one ovary developed a preovulatory sized follicle, although on one occasion both ovaries developed a large follicle, which ovulated within $46 \mathrm{~h}$ after mating. Within 2-4 days after ovulation, a corpus luteum was discernible and often remained visible into the next follicular phase (Fig. 2c). Formation of a corpus haemorrhagicum by the ovulating follicle was not observed.

\section{Pregnancy detection and evaluation}

Early pregnancy in the Sumatran rhinoceros appeared similar to that in the domestic horse (Ginther, 1979, 1995) and white rhinoceros (Radcliffe et al., 1997). A 3-5 mm echogenic embryonic vesicle was detected using ultrasonography as early as day 14 after mating and was usually located in or near the uterine body (Fig. 4a). The embryonic vesicle was mobile within the uterine lumen and grew rapidly, expanding to $10 \mathrm{~mm}$ by day 16 . The embryo developed from the ventral surface of the vesicle by day 21 (Fig. 4b). As the embryo grew, it rotated dorsally (Fig. 4c) before dropping down, suspended by the umbilicus, within the allantoic sac. A heartbeat was detected by day 26 and the fetal heart rate was 153 beats per min on day 52 . 
The first pregnancy occurred in September 1997 and was monitored closely until day 35 of gestation. The next evaluation (day 42) revealed embryo loss. The embryonic vesicle had collapsed and only remnants of fetal tissues were observed. The second pregnancy occurred in March 1998 and was examined using ultrasonography at 9-18 day intervals. By day 70, a completely formed fetus was visualized suspended from the umbilicus (Fig. 4d). On day 79 , the fetus appeared normal showing limb mobility and a strong heartbeat. Examination on day 90 revealed no signs of a fetus or placental membranes. The only evidence that the female had been pregnant was a thickening of the uterine endometrium that slowly dissipated during the subsequent weeks. The third pregnancy (August 1998) was detected on day 16, and the female was not examined again until day 30 when the remains of a collapsed embryonic vesicle were observed in the caudal opening of the cervix.

Pregnancies were associated with an extended period of increased serum progesterone concentrations (pregnancies 1-3; Fig. 3b) and faecal progestins (pregnancy 1; Fig. 3a). The first two pregnancy losses were characterized by a decrease in progesterone concentrations accompanied by rapid follicular growth and re-mating within 2 weeks. Although the third pregnancy was lost by day 30, serum progesterone concentrations remained high for about 60 days. This pregnancy resulted from the only observed double ovulation. However, peak progesterone concentrations were not higher in the presence of two corpora lutea than with a single corpus luteum.

\section{Serum $L H$}

Serum samples collected from female no. 29 after mating contained increased $(P<0.05) \mathrm{LH}$ concentrations $\left(14.7 \pm 7.8 \mathrm{ng} \mathrm{ml}^{-1}\right)$, which were almost 30 -fold higher on average than those in samples collected on other days of the oestrous cycle $\left(0.52 \pm 0.71 \mathrm{ng} \mathrm{m}^{-1}\right.$; Fig. 5). On day 306 , serum was collected approximately $2 \mathrm{~h}$ before copulation, and the LH concentration was baseline. On day 327 (16 January 1998) and day 535 (8 August 1998), serum samples were obtained $1-2 \mathrm{~h}$ before and 4 or $1 \mathrm{~h}$ after copulation, respectively. In each case, LH concentrations were baseline in samples collected before mating and increased (3.5 ng ml-1 and > $20 \mathrm{ng} \mathrm{ml}^{-1}$, respectively) in the samples collected after mating.

After mating four times at exactly 21 day intervals (from November to January; from day 264 to day 327), animals were expected to mate again on 6 February 1998 (day 348); however, inclement weather made it impossible to introduce the animals. LH concentrations in serum collected each day from 5 February to 10 February 1998 (from day 347 to day 352) did not increase above baseline.

Serum samples collected from female no. 27 were also analysed for LH (Fig. 5). The baseline LH concentration in this female $\left(2.43 \pm 0.66 \mathrm{ng} \mathrm{m}^{-1}\right)$ was higher $(P<0.05)$ than that for female no. 29, but LH peaks were not observed.

\section{Discussion}

A female Sumatran rhinoceros used in this study was found to be an induced ovulator. Although induced (or reflex) ovulation is not unusual it has not been documented in any other species of rhinoceros. Furthermore, this is the first report of induced ovulation within the Perrisodactyla (Equidae, Tapiridae and Rhinocerotidae).

Similar to the domestic horse (Ginther, 1995), the Sumatran rhinoceros developed large multiple antral follicles (> $50 \mathrm{~mm}$ in circumference and $>15 \mathrm{~mm}$ in diameter) on both ovaries; however, there were differences with respect to ovarian dynamics. For example, distinct follicular waves reported in horses (Ginther, 1993) were not apparent in the Sumatran rhinoceros during periods in which mating did not occur. Sumatran rhinoceros preovulatory follicles (19-25 mm) were smaller than those reported in the horse (35-55 mm) (Ginther, 1995) and the African white rhinoceros $(30 \mathrm{~mm})$ (Radcliffe et al., 1997). Furthermore, follicles grew beyond preovulatory size when ovulation was not induced by mating. On the basis of these observations, it is apparent that attempts to breed the female when follicles reached $28-30 \mathrm{~mm}$ in diameter failed because the periovulatory phase and oestrus had passed. A somewhat similar observation has been reported in the dromedary camel. Preovulatory camel follicles are 9-19 $\mathrm{mm}$ in diameter, and larger follicles ( $\geqslant 30 \mathrm{~mm}$ in diameter) fail to ovulate after mating (Skidmore et al., 1996).

Luteinized follicles have been reported in horses, but are considered irregular and associated primarily with the transition from seasonal anoestrus to the spring breeding season (Ginther, 1990, 1995). In the present study, the female Sumatran rhinoceros frequently developed luteinized follicles throughout the year. These follicles were determined to be anovulatory on the basis of (i) the ballottement test (Ginther, 1995); (ii) that collapse of the follicle was not observed; (iii) the follicle was $\geqslant 20 \mathrm{~mm}$ in diameter for at least 7 days; and (iv) tissue gradually displaced the fluid-filled centre over 11-23 days. These structures formed most frequently when animals were not mated and were usually preceded by the growth of a relatively large ( $\geqslant 80 \mathrm{~mm}$ circumference) follicle.

Although only one reproductively active animal was evaluated in this study, similar anovulatory haemorrhagic structures have been identified using ultrasonography in several Sumatran rhinoceroses in Indonesia and Malaysia, providing evidence that the formation of these structures is not an individual-specific characteristic (N. C. Schaffer, unpublished). However, the presence of anovulatory haemorrhagic structures may not be a normal occurrence but an artefact of captive management. Although luteinized follicle formation is not a common characteristic in most species, it has been reported in several induced ovulators (bulldog bats: Rasweiler, 1984; mink: Douglas et al., 1994; Zambian common mole-rats: Willingstorfer et al., 1998) and is thought to result from a lack of ovulatory stimulus. Wild female rhinoceroses are likely to mate and thus 

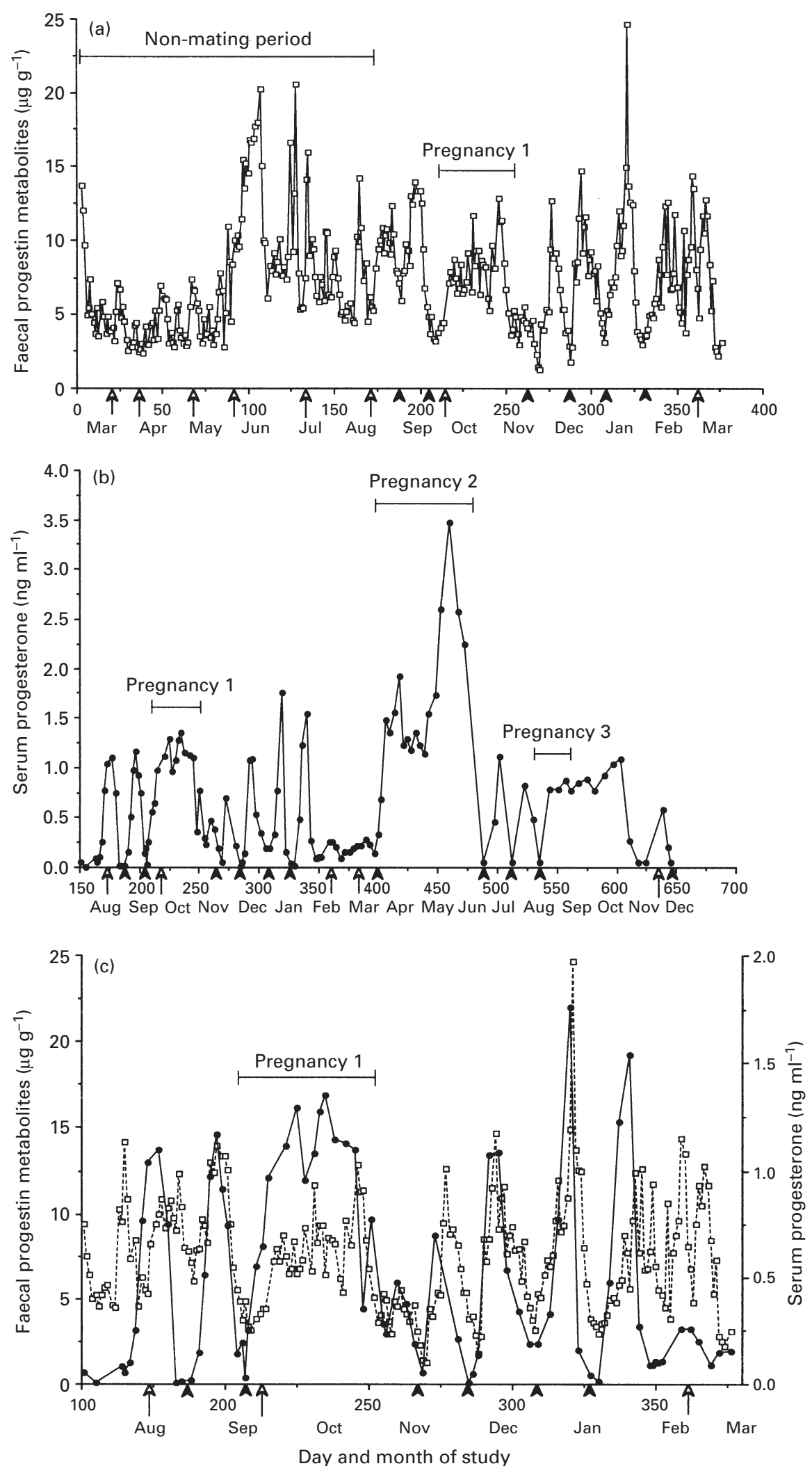

Fig. 3. Summary of the endocrine data from female Sumatran rhinoceros no. 29 during the 22 month study (from day 1 to day 647 ). (a) Faecal progestin metabolites measured from day 1 to day 375 ( $\square$ ); (b) serum progesterone measured from day 151 to day 647 (@) and (c) combined profiles where (a) and (b) overlap. Horizontal bars represent pregnancy intervals. Solid arrowheads indicate days of mating. Open arrows indicate the appearance of luteinized follicles. 

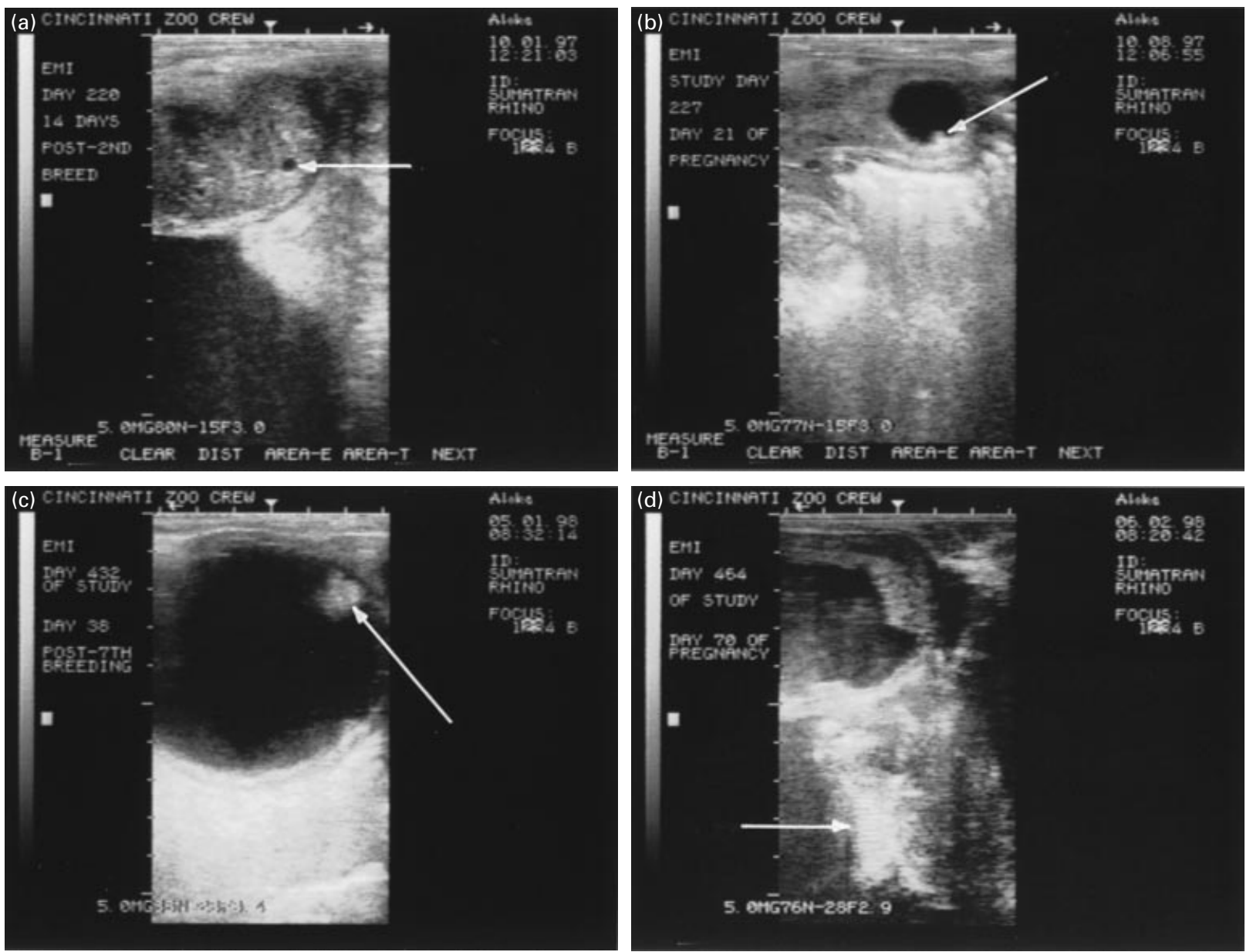

Fig. 4. Ultrasound images of early pregnancy in Sumatran rhinoceros no. 29. (a) Day 14 after mating, arrow indicates $4 \mathrm{~mm}$ embryonic vesicle located within the caudal portion of the right uterine horn entering the uterine body; (b) day 21, the embryo (arrow) is visible developing from the ventral surface of the vesicle; (c) day 38, the embryo (arrow) is located dorsally within the vesicle; and (d) day 70, the fetus (arrow) is suspended vertically by the umbilicus.

ovulate when they come into oestrus. In contrast, captive animals are rarely in breeding situations and, therefore, ovulatory stimuli may be lacking.

Mechanisms for inducing ovulation vary among reflex ovulators. Female rabbits will ovulate in response to another female mounting them (Goodman, 1998). In camels, seminal fluid induces ovulation (Chen et al., 1985). In cats, penile spines may contribute to the mechanical induction of ovulation (Aronson and Cooper, 1967), a theory supported by the fact that vaginal stimulation with a probe effectively induces ovulation in queens (Greulich, 1934). The stimulus for ovulation in the Sumatran rhinoceros appears to be associated with mating activity (mounting and attempted copulation), but does not require successful intromission as demonstrated on two occasions when the male failed to copulate fully, but the female ovulated. In both cases, although full penile penetration and ejaculation were not achieved, partial insertion of the penis into the vaginal opening and emission of fluid from the penis were observed. Therefore, both mechanical stimulation, caused by mounting and partial penile insertion, and seminal fluid exposure are possible mechanisms for inducing ovulation in this species of rhinoceros.

Blood was collected once or twice each day, so the exact timing of the $\mathrm{LH}$ surge relative to copulation was not characterized. However, it is clear that this species of rhinoceros differs from the horse, which shows an extended period of increased $\mathrm{LH}$ concentrations during oestrus and for several days after ovulation (Geschwind et al., 1975). Instead, the Sumatran rhinoceros appeared more like camels and cats, which experience a detectable increase in $\mathrm{LH}$ concentrations within $1 \mathrm{~h}$ after mating and an LH peak within 2-4 h (Concannon et al., 1980; Marie and Anouassi, 1986). LH concentrations were always baseline just before mating, increased up to 100-fold within hours after copulation and returned to baseline the next day. Therefore, in the Sumatran rhinoceros, a single mating appeared to elicit an LH surge that lasted $<22 \mathrm{~h}$ and induced ovulation.

Heistermann et al. (1998) reported a 25 day reproductive 


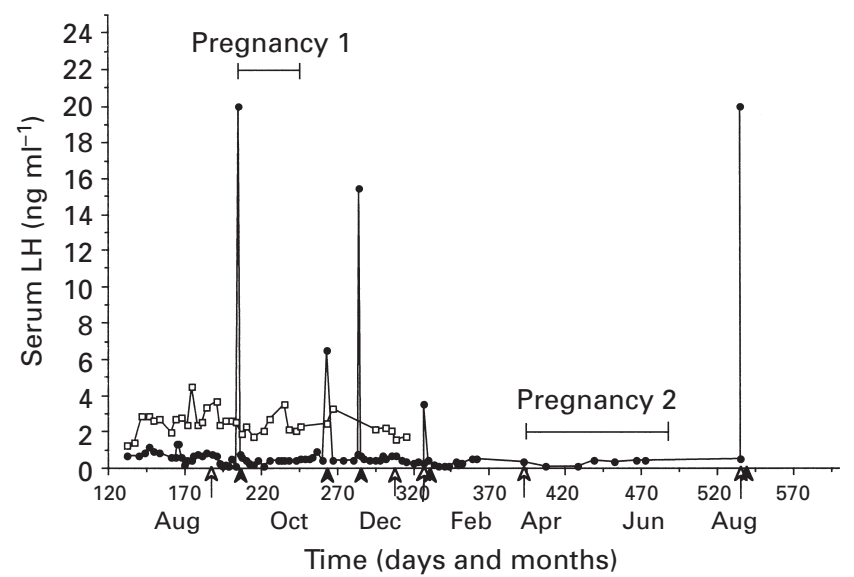

Fig. 5. Serum LH concentrations for female Sumatran rhinoceroses no. $29(\bullet)$ and no. $27(\square)$. Solid arrowheads indicate blood samples collected from no. 29 after mating (1-4 h after copulation). Open arrows indicate blood samples collected $1-3 \mathrm{~h}$ before mating.

cycle in a female Sumatran rhinoceros on the basis of faecal and urine endocrine monitoring over a 60 day period. The female rhinoceros used in the present study mated with the male and ovulated at 21 day intervals, indicating a reproductive cycle similar to but slightly shorter than that reported by Heistermann et al. (1998). This small difference could be due to individual variation or the fact that the female in this study was mating. Regardless of this variation, it appears that the reproductive cycle of the Sumatran rhinoceros is more like that of the African black rhinoceros (25 days) (Schwarzenberger et al., 1993; Berkeley et al., 1997; Radcliffe et al., 1997) than the reproductive cycles of the African white (30-70 days) (Schwarzenberger et al., 1998; Patton et al., 1999) and Indian rhinoceroses (39-64 days), which are longer (Kasman and Lasley, 1981; Roth and Brown, 1999).

Both faecal progestin and serum progesterone profiles reflected physiological changes in the female reproductive status. Therefore, reproductive monitoring in this species could be conducted using faeces instead of serum. However, when the animals were not mating and luteinized follicles produced varied concentrations of progesterone ranging from 0.2 to $>1.0 \mathrm{ng} \mathrm{ml}^{-1}$, the faecal progestin data were more difficult to interpret. If endocrine monitoring had been the only technique used in this study, the occurrence of induced ovulation may not have been detected. Fluctuations in progesterone concentrations would probably have been interpreted as luteal phases resulting from spontaneous, albeit irregular, ovulations instead of luteinized follicles.

The cause of pregnancy failure was not determined and may have been different in each case. The timing of the first pregnancy loss (from day 36 to day 42) coincides with the initiation of implantation in horses (Ginther, 1979). The embryo implanted in the second pregnancy and the fetus appeared to develop normally until day 79 when a heartbeat and fetal head and limb movement were observed using ultrasonography. Fetal loss during this pregnancy was especially difficult to explain as the pregnancy had advanced beyond the stage when most equine pregnancies are lost (Ginther, 1995). The third failed pregnancy (by day 30) was similar to cases of early embryonic loss that occur before implantation in $6 \%$ of healthy fertile mares (Ginther, 1995).

The prevalence of early pregnancy loss in captive rhinoceros populations is unknown. Several African black and white rhinoceroses are mated repeatedly without producing calves (Schwarzenberger et al., 1998; Patton et al., 1999; Roth and Brown, 1999). Increased use of ultrasonography will be key in determining whether these animals experience pregnancy loss or simply fail to become pregnant. Spontaneous abortion has been reported in a 29-year-old black rhinoceros, which subsequently was supplemented with progesterone and successfully carried a term pregnancy (Berkeley et al., 1997). In addition, early embryo loss (by day 28) associated with endometritis has been documented using ultrasonography in a white rhinoceros (Radcliffe et al., 1997). However, the female Sumatran rhinoceros in this study was young, appeared healthy and did not show any uterine pathology. Furthermore, after the loss of the third pregnancy, the female experienced an extended luteal phase that lasted $\geqslant 30$ days after embryo loss was detected. Therefore, at least in one case, premature luteolysis did not appear to be responsible for the failed pregnancy.

In pregnant mares, chorionic girdle cells invade the maternal endometrium 35-40 days after ovulation and form equine chorionic gonadotrophin (eCG)-secreting endometrial cups (Ginther, 1979). Serum concentrations of eCG reach peak concentrations about 60 days after ovulation. On the basis of DNA analyses, Sherman et al. (1997) suggested that pregnant African and Indian rhinoceroses do not produce a chorionic gonadotrophin. In support of this finding, data from the present study provide preliminary evidence that a chorionic gonadotrophin homologous to eCG is not produced by the Sumatran rhinoceros during early pregnancy. If the female Sumatran rhinoceros produced eCG, the LH assay, which uses an antibody to the LH/eCG $\beta$ subunit, should have revealed an increase in eCG concentrations during the pregnancy that was sustained until day 79 of gestation.

The older female Sumatran rhinoceros used in the present study appeared infertile. The female had small inactive ovaries, increased LH concentrations and baseline progesterone concentrations, which are all characteristics of reproductive senescence (Vom Saal et al., 1994). In addition, the uterus contained a large mass. Unexplained uterine pathology has been detected in several Sumatran rhinoceroses in Malaysia (Schaffer et al., 1994; Kahn et al., 1999) and is becoming a serious concern.

Results from the present study provide an insight into several aspects of the reproductive physiology of the Sumatran rhinoceros. Combined data from ultrasound and 
endocrine analyses provided evidence of patterns of follicular growth and induced ovulation and enabled documentation of early pregnancy for the first time in this species. Furthermore, the combined use of ultrasonography and progesterone monitoring proved a successful repeatable method for predicting oestrus and largely reduced the risk of aggressive interactions associated with introducing males to non-oestrous females.

The authors thank the Los Angeles and Bronx Zoos for loaning their female rhinos to the Cincinnati Zoo for breeding. The authors also extend their tremendous gratitude to the rhino keeper staff of the Cincinnati Zoo and Botanical Garden, especially P. Reinhardt, S. Yelverton and T. Tenhenfeld for their dedication to the animals and for providing critical technical support throughout the project. The authors are also grateful to the Cincinnati Zoo Volunteer Observers for diligently recording animal behavioural data during introductions. Appreciation also goes to E. Maruska, Executive Director of the Cincinnati Zoo and Botanical Garden, and T. Foose, Asian Rhino Specialist Group Program Officer and International Rhino Foundation Program Director, for their helpful input on this project and long-term commitment to saving this species from extinction. This research was supported in part by the International Rhino Foundation and the Center for Research of Endangered Wildlife's C. and E. Lindner Post-doctoral Fellowship.

\section{References}

Aronson LR and Cooper ML (1967) Penile spines of the domestic cat: their endocrine-behavior relations Anatomical Record 157 71-78

Berkeley EV, Kirkpatrick JF, Schaffer NE, Bryant WM and Threlfall WR (1997) Serum and faecal steroid analysis of ovulation, pregnancy and parturition in the black rhinoceros (Diceros bicornis) Zoo Biology 16 121-132

Brown JL, Wasser SK, Wildt DE and Graham LH (1994) Comparative aspects of steroid hormone metabolism and ovarian activity in felids, measured non-invasively in feces Biology of Reproduction 51 776-786

Brown JL, Schmitt DL, Bellem A, Graham LH and Lehnhardt J (1999) Hormone secretion in the Asian elephant (Elephas maximus): characterization of ovulatory and anovulatory luteinizing hormone surges Biology of Reproduction 61 1294-1299

Chen BX, Yuen ZX and Pan GW (1985) Semen-induced ovulation in the bactrian camel (Camelus bactrianus) Journal of Reproduction and Fertility 74 335-339

Concannon P, Hodgson B and Lein D (1980) Reflex LH release in estrous cats following single and multiple copulations Biology of Reproduction $23111-117$

Douglas DA, Pierson RA and Murphy BD (1994) Ovarian follicular development in mink (Mustela vison) Journal of Reproduction and Fertility $100583-590$

Foose TJ and Reece RW (1998) American Zoological and Aquarium Association Species Survival Plan Rhinoceros Masterplan. The Wilds, Columbus

Foose TI and Van Strien N (1997) Asian Rhinos: Status Survey and Conservation Action Plan, New Edition. IUCN Publication Services, Cambridge

Geschwind II, Dewey R, Hughes JP, Evans JW and Stabenfeldt GH (1975) Plasma LH levels in the mare during the oestrous cycle Journal of Reproduction and Fertility Supplement 23 207-212

Ginther OJ (1979) Reproductive Biology of the Mare: Basic and Applied Aspects Equiservices Publishing, Cross Plains

Ginther OJ (1990) Folliculogenesis during the transitional period and early ovulatory season in mares Journal of Reproduction and Fertility $\mathbf{9 0}$ $311-320$
Ginther OJ (1993) Major and minor waves during the equine estrous cycle Journal of Equine Veterinary Science 13 18-25

Ginther OJ (1995) Ultrasonic Imaging and Animal Reproduction: Horses Book 2 Equiservices Publishing, Cross Plains

Goodman AL (1998) Reflex (induced) ovulation. In Encyclopedia of Reproduction pp 206-211 Eds E Knobil and JD Neill. Academic Press, San Diego

Greulich WW (1934) Artificially induced ovulation in the cat (Felis domesticus) Anatomical Record 58 217-224

Heistermann M, Agil M and Hodges JK (1998) Metabolism and excretion of oestradiol-17 $\beta$ and progesterone in the Sumatran rhinoceros (Dicerorhinus sumatrensis) Animal Reproduction Science 53 157-172

Hodges JK and Green DI (1989) The development of an enzymeimmunoassay for urinary pregnanediol-3-glucuronide and its application to reproductive assessment in exotic mammals Journal of Zoology London 219 89-99

IUCN (1996) The Red List of Threatened Animals IUCN Publications Service, Cambridge

Jaszczak SE (1983) Anovulatory luteal cycles in primates Contraception 27 505-514

Kasman AAH and Lasley BL (1981) Estrogen excretory patterns in the Indian rhinoceros (Rhinoceros unicornis) determined by simplified urinary analysis American Journal of Veterinary Research 42 251-255

Kasman LH, Ramsay EC and Lasley BL (1986) Urinary steroid evaluations to monitor ovarian function in exotic ungulates: III Estrone sulfate and pregnanediol-3-glucuronide excretion in the Indian rhinoceros (Rhinoceros unicornis) Zoo Biology 5 355-361

Khan MKM, Roth TL and TJ Foose (1999) In situ and ex situ efforts to save the Sumatran rhinoceros (Dicerorhinus sumatrensis) Proceedings 7th World Conference on Breeding Endangered Species pp 163-174

Marie M and Anouassi A (1986) Mating-induced luteinizing hormone surge and ovulation in the female camel (Camelus dromedarius) Biology of Reproduction 35 792-798

Munro CJ and Stabenfeldt G (1984) Development of a microtiter plate enzyme immunoassay for the determination of progesterone Journal of Endocrinology $10141-49$

Patton ML, Swaisgood RR, Czekala NM, White AM, Getter GA, Montagne JP, Rieches RG and Lance VA (1999) Reproductive cycle length and pregnancy in the southern white rhinoceros (Ceratotherium siumu simum) as determined by faecal pregnane analysis and observations of mating behavior Zoo Biology 18 111-127

Radcliffe RW, Czekala NM and Osofsky SA (1997) Combined serial ultrasonography and faecal progestin analysis for reproductive evaluation of the female white rhinoceros (Ceratotherium simum simum): Preliminary results Zoo Biology 16 445-456

Rasweiler JJ (1984) Reproductive failure due to the entrapment of oocytes in luteinized follicles of the little bulldog bat (Noctilio albiventris) Journal of Reproduction and Fertility 71 95-101

Roth TL and Brown JL (1999) Is there any rhyme or reason to rhino reproduction? A summary of reproductive characteristics, speciesspecificities and challenges for the future Proceedings of the American Association of Zoo Veterinarians Annual Conference pp 97-99

Schaffer NE, Zainal-Zahari Z, Suri MSM, Jainudeen MR and Jeyendran RS (1994) Ultrasonography of the reproductive anatomy in the Sumatran rhinoceros Journal of Zoo and Wildlife Medicine 25 337-348

Schwarzenberger F, Francke R and Goltenboth R (1993) Concentrations of faecal immunoreactive progestagen metabolites during the oestrous cycle and pregnancy in the black rhinoceros (Diceros bicornis michaeli) Journal of Reproduction and Fertility 98 285-291

Schwarzenberger F, Walzer C, Tomasova K, Vahala J, Meister J, Goodrowe KL, Zima J, Strauss G and Lynch M (1998) Faecal progesterone metabolite analysis for non-invasive monitoring of reproductive function in the white rhinoceros Animal Reproduction Science $\mathbf{5 3}$ 173-190

Sherman GB, Lund LA, Bunick D and Winn RJ (1997) Characterization and phylogenetic significance of rhinoceros luteinizing hormone beta $(\mathrm{LH} \beta)$ subunit messenger RNA structure, complementary DNA sequence and gene copy number Gene 195 131-139

Skidmore JA, Billah M and Allen WR (1996) The ovarian follicular wave 
pattern and induction of ovulation in the mated and non-mated onehumped camel (Camelus dromedarius) Journal of Reproduction and Fertility 106 185-192

Vom Saal FS, Finch CE and Nelson JF (1994) Natural history and mechanisms of reproductive aging in humans, laboratory rodents and other selected vertebrates. In The Physiology of Reproduction Vol. 2 pp 1213-1314 Eds E Knobil and JD Neill. Academic Press, San Diego
Willingstorfer WJ, Burda H and Winckler J (1998) Ovarian growth and folliculogenesis in breeding and non-breeding females of a social rodent, the Zambian common mole-rat, Cryptomys sp. Journal of Morphology 237 33-41

Received 6 December 1999

Accepted 7 July 2000 